\title{
A GAGUEIRA SOB DIFERENTES OLHARES: ANÁLISE COMPARATIVA DAS ABORDAGENS DE QUATRO AUTORAS
}

\author{
Stuttering under different prisms: the comparative analysis based \\ on four specialists
}

Rosivânia de Almeida Moraes ${ }^{(1)}$, Kátia Nemr ${ }^{(2)}$

\begin{abstract}
RESUMO
Objetivo: analisar comparativamente quatro abordagens em gagueira quanto aos aspectos definição, etiologia, avaliação, terapia; demonstrar justificativas para a ausência de disfluências gagas no monólogo. Métodos: revisão bibliográfica sistemática das publicações das autoras: Ana Maria Schiefer, Claudia Regina Furquim de Andrade, Silvia Friedman e Isis Meira, designadas como abordagens 1, 2, 3, 4. Resultados: assemelham-se em: Definição - 1 e 2 quanto ao caráter descritivo, 2 e 3 quanto a autoavaliação; Etiologia: 1, 2 e 4 quanto ao fator orgânico, 2, 3 e 4 quanto a implicação psicológica, 2 e 3 quanto a ambiental; Avaliação - 1 e 2 quanto ao critério quantitativo, 1, 2, 3 e 4 quanto ao qualitativo; Terapia - 1 e 2. A ausência de disfluências gagas se justificou pelas perspectivas: em 1, pressão do tempo e pragmática; em 2, ajuste neurolinguístico e motor; em 3, paradoxo básico, em 4, antecipação, ansiedade e medo. Conclusão: 1 e 2 se assemelham quanto definição, etiologia, avaliação, terapia; 1 e 3 quanto avaliação; 2 e 3 quanto definição, etiologia, avaliação; 1 e 4, 2 e 4, 3 e 4 quanto etiologia, avaliação, terapia. As semelhanças mostraram-se parciais, dada a especificidade do referencial teórico de cada abordagem. A ausência de disfluências gagas justificou-se pela inexistência da necessidade de ajuste ao interlocutor e de intenção comunicativa em 1, de ajuste na formulação lingüística e temporal em 2, pela ausência de receio de julgamento em 3, de antecipação, ansiedade e medo em 4.
\end{abstract}

DESCRITORES: Gagueira; Comunicação; Relações Interpessoais

\section{INTRODUÇÃO}

A Gagueira tem sido amplamente estudada por diferentes áreas do conhecimento ${ }^{1}$ dada sua complexidade e possibilidades de interpretação ${ }^{2}$. Teorias, terminologia e conceituação são bastante diversificadas ${ }^{1,3,4}$, fundamentando-se em diferentes correntes do pensamento científico ${ }^{5,6}$, e direcionando o olhar dos estudiosos da gagueira para teorias orgânicas, psicológicas e sociais ${ }^{1,7-9}$, o que permite uma infinidade de leituras do "mesmo" objeto de estudo.

O conhecimento destes diferentes olhares é fundamental para o embasamento da prática clínica, na qual nos deparamos com algumas questões importantes como, qual a justificativa para a ausência de

(1) Fonoaudióloga; Secretaria da Saúde do Governo do Estado de São Paulo; Prefeitura do Município de São Caetano do Sul; Especialização em Linguagem.

(2) Fonoaudióloga; Professora Concursada da Universidade de São Paulo; Doutora em Psicologia Social pela Universidade de São Paulo. disfluências gagas no monólogo, quando a fala não tem função comunicativa ${ }^{10}$, relatada por pacientes adultos e observada em crianças gagas durante atividade lúdica, situação que pode levar à identificação da gagueira como transtorno da relação interpessoal.

Este questionamento assume importância teórico - prática uma vez que, se tomada pelo senso comum, gagueira/ ansiedade/ medo estabelecem relação etiológica, bastando ficar calmo para deixar de gaguejar, inferência largamente refutada por vários autore ${ }^{9,11-18}$, considerando-se as teorias sobre etiologia e funcionamento da gagueira.

Tentando entender a relação monólogo - ausência de intenção comunicativa - fluência, diálogo comunicação - gagueira foram encontrados na literatura alguns estudos sobre ansiedade social, emoções e gagueira ${ }^{19-21}$ que estabelecem relação positiva entre estes fatores, e outros que destacam a importância de se considerar a pragmática ${ }^{22,23}$ na terapia da gagueira, apontando para a influência dos diferentes contextos comunicativos na fluência de pessoas que gaguejam, sem, no entanto, serem alu- 
sivos ao monólogo.

Considerando a importância do conhecimento teórico sobre a gagueira, este estudo tem por objetivos: analisar comparativamente quatro abordagens teóricas, com base nos parâmetros definição, etiologia, avaliação e terapia; demonstrar justificativas para a ausência de disfluências gagas no monólogo, considerando as teorias analisadas.

\section{MÉTODOS}

Selecionaram-se as abordagens com base na representatividade de suas autoras, considerando que são importantes produtoras de conhecimento em gagueira e professoras da graduação e/ou pós-graduação dos cursos de Fonoaudiologia de Universidades reconhecidas em nível nacional e/ou internacional, promovendo a formação teórico - prática de muitos profissionais da área. São elas: Abordagem Psicolingüística da Fluência, elaborada por Ana Maria Schiefer, designada como abordagem 1, Abordagem Neurolingüística e Motora da Gagueira, elaborada por Claudia Regina Furquim de Andrade, designada como abordagem 2, Abordagem na Vertente Contextualizada - Análise de Discurso, formulada por Silvia Friedman, designada como abordagem 3 e Abordagem Fenomenológica da Fluência, elaborada por Isis Meira, designada como abordagem 4.

Procedeu-se ao levantamento bibliográfico da produção das autoras pela Internet, no site www.cnpq.br, na Plataforma Lattes, buscando suas publicações apresentadas no Currículo Lattes.

A seleção e localização dos artigos publicados em periódicos indexados foram realizadas pela Biblioteca Virtual da Saúde, site da Bireme (www.bireme.br). Os descritores utilizados foram: gagueira, stuttering e tartamudeo, nas bases de dados Lilacs, Medline e Scielo.

Artigos publicados em periódicos não indexados, livros, capítulos de livros e teses foram pesquisados e selecionados na Biblioteca Central da Escola Paulista de Medicina, Biblioteca do Cefac (CEFAC - Saúde e Educação), Biblioteca da Universidade Metodista de São Bernardo do Campo ou adquiridos em livrarias.

Os dados foram apresentados na forma descritiva por meio de figuras contendo a síntese das abordagens segundo os tópicos que fundamentaram os objetivos da pesquisa.

\section{RESULTADOS}

As sínteses das abordagens analisadas estão apresentadas nas Figuras abaixo.

A Figura 1 apresenta a síntese da abordagem 1. A Figura 2 apresenta a síntese da abordagem 2. A Figura 3 apresenta a síntese da abordagem 3 . A Figura 4 apresenta a síntese da abordagem 4.

As comparações das abordagens conforme os parâmetros estudados estão apresentadas nas Figuras abaixo.

A Figura 5 apresenta quadro comparativo do parâmetro Definição.

A Figura 6 apresenta quadro comparativo do parâmetro Etiologia.

A Figura 7 apresenta quadro comparativo do parâmetro Avaliação.

A Figura 8 apresenta quadro comparativo do parâmetro Terapia.

As justificativas para a ausência de disfluências gagas no monólogo com base nas abordagens estudadas estão sintetizadas na Figura 9.

\begin{tabular}{|c|c|}
\hline $\begin{array}{l}\text { Definiçào } \\
\text { da } \\
\text { Gagueira }\end{array}$ & $\begin{array}{l}\text { Ruptura na transiçäo nos diferentes niveis lingüisticos }{ }^{24} \text {, caracterizada por repetiçōes } \\
\text { ou prolongamentos involuntários, normalmente acompanhados por movimentos } \\
\text { corporais ou faciais. }\end{array}$ \\
\hline $\begin{array}{l}\text { Etiologia } \\
\text { da } \\
\text { Gagueira }\end{array}$ & 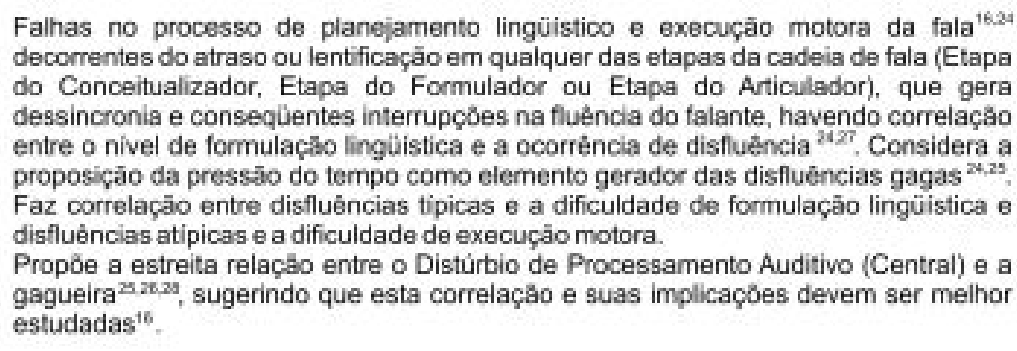 \\
\hline Avaliaçäo & $\begin{array}{l}\text { a) Qualitativa: disfluetncias tipicas X disfluências atipicas }{ }^{242 \pi} \text {. } \\
\text { b) Quantitativa } a^{24} 25 \\
\text { - Gagueira: } 3 \% \text { cu mais de atipicas elou } 10 \% \text { de disf. totais; } \\
\text { - Limitrofe: } 2 \text { a } 3 \% \text { de atipicas elou } 10 \% \text { ou mais de disf. totais; } \\
\text { - Disf. Tipicas: menos de } 2 \% \text { de atipicas e de } 10 \% \text { de tipicas. }\end{array}$ \\
\hline Terapia & $\begin{array}{l}\text { Habilidades de fala: respiração, fonação, articulação e prosódia. } \\
\text { Treinamento das Habilidades Auditivas alteradas } \\
\text { 28. }\end{array}$ \\
\hline
\end{tabular}

Figura 1 - Síntese dos aspectos pesquisados em relação à Abordagem 1 


\begin{tabular}{|c|c|}
\hline $\begin{array}{l}\text { Definição } \\
\text { da } \\
\text { Gagueira }\end{array}$ & $\begin{array}{l}\text { Gagueira não é um problema de fala, mas um problema da identidade do sujeito "que } \\
\text { luta para nāo produzir um padrăo de fala que prevê", para nāo se mostrar com uma } \\
\text { imagem estigmatizada de falante11. }\end{array}$ \\
\hline Etiologia & 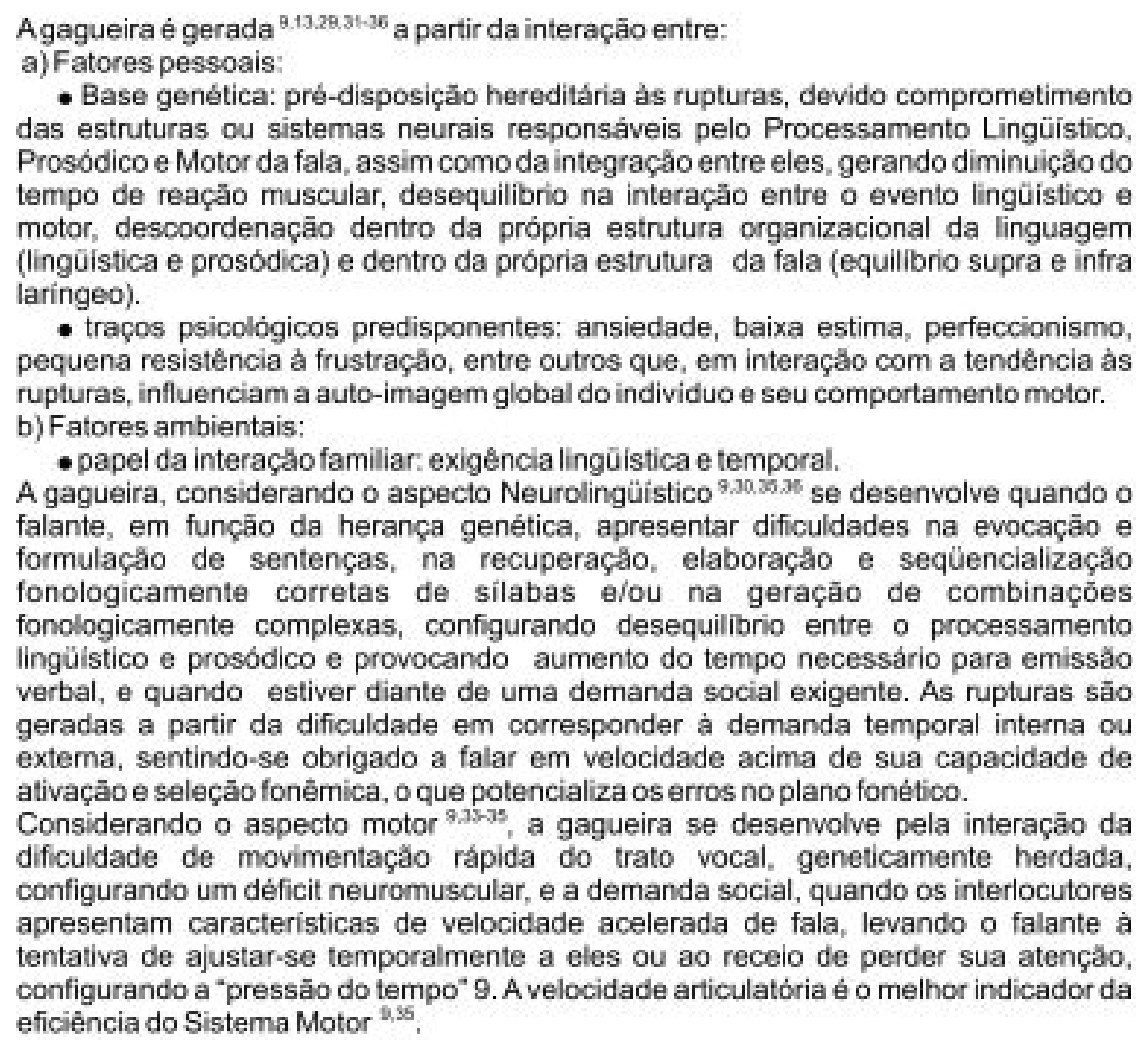 \\
\hline Avaliação & 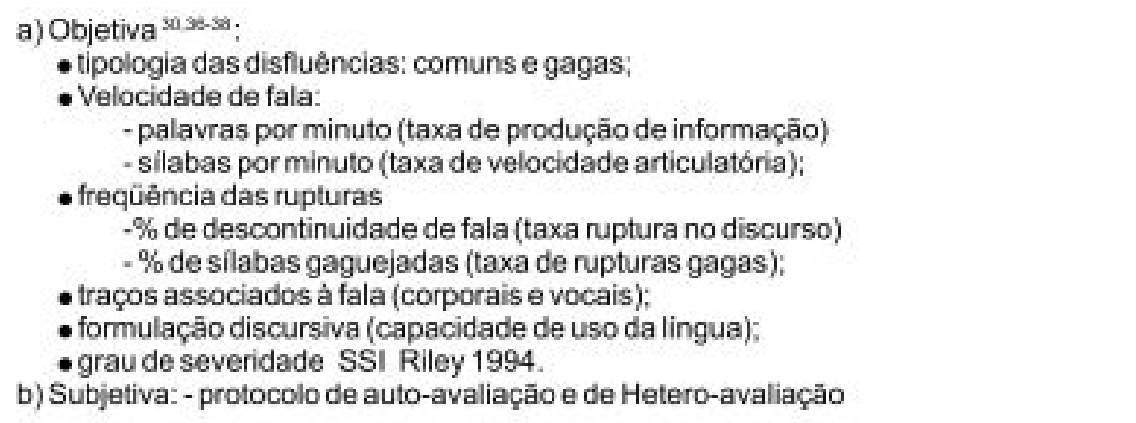 \\
\hline Terapia & 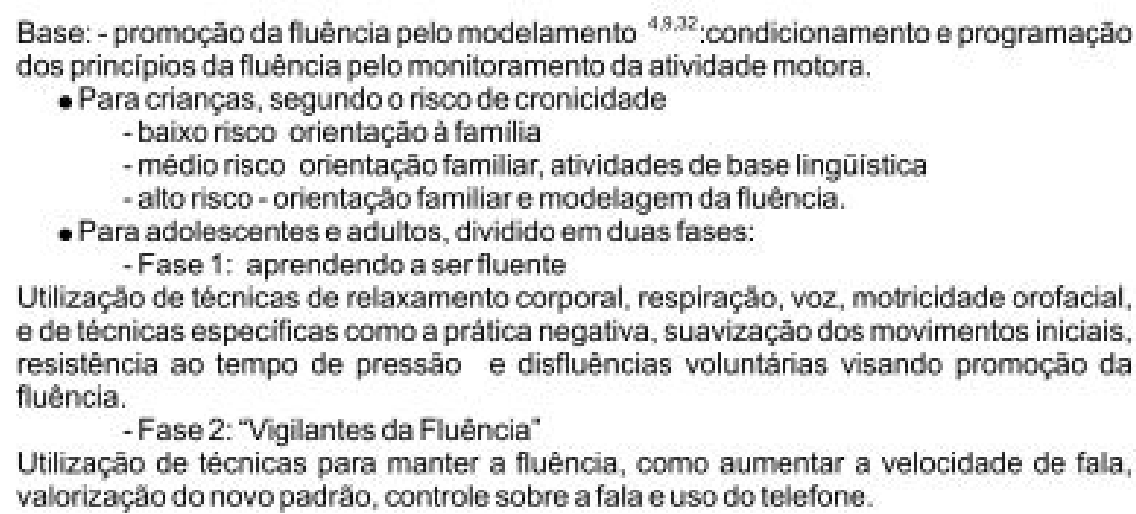 \\
\hline
\end{tabular}

Figura 2 - Síntese dos aspectos pesquisados em relação à Abordagem 2 


\begin{tabular}{|c|c|}
\hline $\begin{array}{l}\text { Definição } \\
\text { da } \\
\text { Gagueira }\end{array}$ & $\begin{array}{l}\text { Gagueira não é um problema de fala, mas um problema da identidade do sujeito "que } \\
\text { luta para não produzir um padrão de fala que prevê", para não se mostrar com uma } \\
\text { imagem estigmatizada de falante" }{ }^{11} \text {. }\end{array}$ \\
\hline Etiologia & $\begin{array}{l}\text { A disfluência é um aspecto natural da fluência }{ }^{7,11,12,15,39} \text {, inerente ao ser humano, e } \\
\text { explicada pela dialética interno X externo. A gagueira é conseqüência }{ }^{7,11,12,15,39,40} \text { do } \\
\text { movimento de consciência do sujeito, determinado pela Ideologia do Bem Falar, } \\
\text { veiculada socialmente e por ele assimilada, que determina a nāo aceitação de um } \\
\text { padrāo de fala com disfluências. Este processo gera, em nivel subjetivo, a Imagem } \\
\text { Estigmatizada de Falante, que tenta prever e antecipar os "desvios", evitando-os } \\
\text { através de um padräo paradoxal (planejar o espontâneo); e em nivel objetivo, os } \\
\text { truques para adiar a gagueira prevista ou disparar a fala, mostrando tensão ao falar. } \\
\text { Este processo privilegia o como se fala" (língua / forma) em detrimento do "que se fala" } \\
\text { (sentido), levando ao silenciamento do sentido }{ }^{7,12} \text {. } \\
\text { A partir desse movimento de consciência elabora o conceito de Gagueira Sofrimento, } \\
\text { que opōe ao conceito de Gagueira Natural, e que se perpetua num Círculo Vicioso "11.15,40 } \\
\text { assim estruturado: năo aceitaçăo das disfluências - tentativa de falar "bem" } \\
\text { controlando o espontåneo (paradoxo básico) aumento de tensăo muscular na } \\
\text { produçăo articulatória intensificaçăo das disfluências (reforçando a Imagem } \\
\text { Estigmatizada) reinicio do ciclo. }\end{array}$ \\
\hline $\begin{array}{l}\text { Avaliação } \\
\text { da } \\
\text { Gagueira }\end{array}$ & $\begin{array}{l}\text { a) Quantitativa: não propõe, considerando que não é a quantidade de disfluências que } \\
\text { determinam a Gagueira Sofrimento, mas a auto-imagem de falante (subjetividade). } \\
\text { b) Qualitativa: análise do discurso, buscando apreender a auto-imagem de falante }{ }^{11} \text {. }\end{array}$ \\
\hline Terapia & 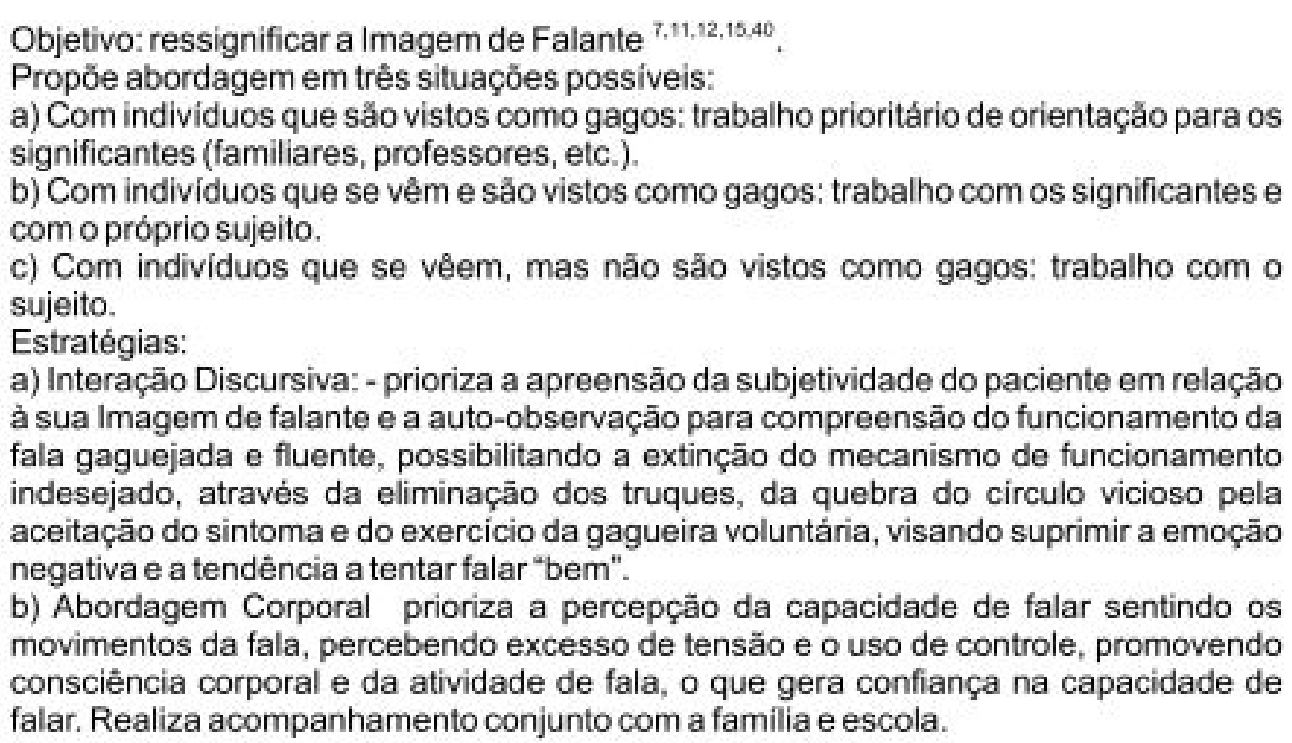 \\
\hline
\end{tabular}

Figura 3 - Síntese dos aspectos pesquisados em relação à Abordagem 3 


\begin{tabular}{|c|c|}
\hline $\begin{array}{l}\text { Definiçăo } \\
\text { da } \\
\text { Gagueira }\end{array}$ & $\begin{array}{l}\text { Năo propö́e definiçäo }{ }^{3.41,42} \text {, entendendo que o fundamental é a busca da essência, } \\
\text { através da observaçāo, descrição e reflexāo da gagueira única e individual que cada } \\
\text { sujeito constrói em seu corpo. }\end{array}$ \\
\hline $\begin{array}{l}\text { Etiologia } \\
\text { da } \\
\text { Gagueira }\end{array}$ & 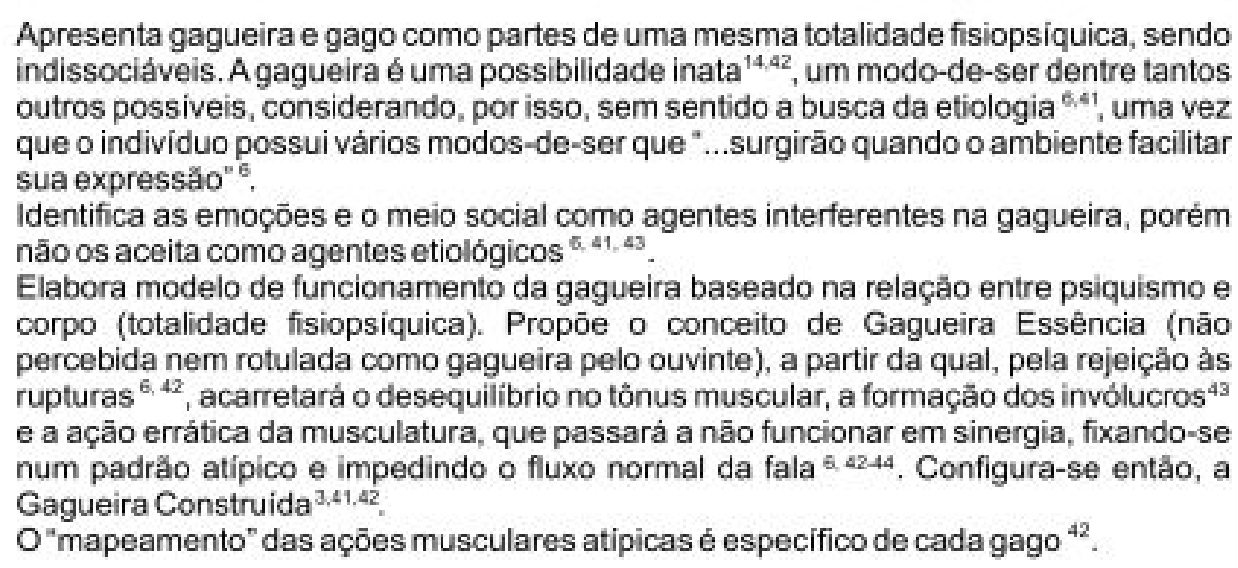 \\
\hline Avaliação & $\begin{array}{l}\text { a) Quantitativa: não propōe }{ }^{3} \text {. } \\
\text { b) Qualitativa: perceber e descrever }{ }^{3} \text {. } \\
\text { 1) Avaliaçăo da gagueira: descrição do mapeamento muscular usado pelo } \\
\text { gago, e da açāo dos músculos; } \\
\text { 2) Avaliação do gago: descrição da sua gagueira pelo gago, avaliando nivel de } \\
\text { consciência e aceitaçäo. }\end{array}$ \\
\hline Terapia & $\begin{array}{l}\text { Objetivo: desconstruçăo da gagueira }{ }^{3,4144} \text {. } \\
\text { a) Trabalho com o gago: } \\
\text { - tomada de consciência do agir, pensar e sentir a gagueira; } \\
\text { - trabalho com o sentimento de rejeiçăo e insatisfaçăo aceitaçăo da gagueira como } \\
\text { parte de si; } \\
\text { •conscientização da relação entre tensão muscular e emoção. } \\
\text { b) Trabalho com a gagueira: } \\
\text { - desenvolvimento da consciência do corpo e da fala } \\
\text { - Conhecimento da gagueira } \\
\text { - reequilibrio do tỏnus muscular dissoluçảo dos invólucros }\end{array}$ \\
\hline
\end{tabular}

Figura 4 - Síntese dos aspectos pesquisados em relação à Abordagem 4

\begin{tabular}{|l|l|l|l|}
\hline \multicolumn{1}{|c|}{ ABORDAGEM 1 } & \multicolumn{1}{|c|}{ ABORDAGEM 2 } & ABORDAGEM 3 & ABORDAGEM 4 \\
\hline $\begin{array}{l}\text { - Descritiva do } \\
\text { comportamento } \\
\text { manifesto }\end{array}$ & $\begin{array}{l}\text { - Descritiva do } \\
\text { comportamento } \\
\text { manifesto }\end{array}$ & $\begin{array}{l}\text { - Auto-avaliação } \\
\text { do sujeito }\end{array}$ & • Não adota \\
& $\begin{array}{l}\text { Auto-avaliação } \\
\text { do sujeito }\end{array}$ & & \\
\hline
\end{tabular}

Figura 5 - Definição da Gagueira 


\begin{tabular}{|c|c|c|c|}
\hline ABORDAGEM 1 & ABORDAGEM 2 & ABORDAGEM 3 & ABORDAGEM 4 \\
\hline - fator hereditário & $\begin{array}{l}\text { - fator hereditário } \\
\text { - fator psicológico } \\
\text { - fator ambiental }\end{array}$ & $\begin{array}{l}\text { - fator contextual } \\
\text { - implicação psico- } \\
\text { lógica }\end{array}$ & $\begin{array}{l}\text { - fator inato } \\
\text { - implicação psico- } \\
\text { lógica }\end{array}$ \\
\hline
\end{tabular}

Figura 6 - Etiologia da Gagueira

\begin{tabular}{|l|l|l|l|}
\hline \multicolumn{1}{|c|}{ ABORDAGEM 1 } & ABORDAGEM 2 & ABORDAGEM 3 & ABORDAGEM 4 \\
\hline$\bullet$ quantitativa & $\bullet$ quantitativa & & \\
$\bullet$ qualitativa & $\bullet$ qualitativa & $\bullet$ qualitativa & $\bullet$ qualitativa \\
\hline
\end{tabular}

Figura 7 - Avaliação da Gagueira

\begin{tabular}{|c|c|c|c|}
\hline ABORDAGEM 1 & ABORDAGEM 2 & ABORDAGEM 3 & ABORDAGEM 4 \\
\hline $\begin{array}{l}\text { - Modelamento da } \\
\text { Fluência }\end{array}$ & $\begin{array}{l}\text { - Modelamento da } \\
\text { Fluência } \\
\text { • Promoção da } \\
\text { Fluência }\end{array}$ & $\begin{array}{l}\text { - Modificação da } \\
\text { Gagueira }\end{array}$ & $\begin{array}{l}\text { - Aspectos de Mo- } \\
\text { delamento da } \\
\text { Fluência e de Mo- } \\
\text { dific a ção da } \\
\text { Gagueira }\end{array}$ \\
\hline
\end{tabular}

Figura 8 - Terapia da Gagueira

\begin{tabular}{|c|c|}
\hline ABORDAGEM 1 & $\begin{array}{l}\text {-Perspectiva da pressāo do tempo } \\
\text { Năo há necessidade de ajuste ao interlocutor. } \\
\text {-Perspectiva da Pragmática } \\
\text { Não há intençăo comunicativa. }\end{array}$ \\
\hline ABORDAGEM 2 & $\begin{array}{l}\text {-Perspectiva Neurolingüistica } \\
\text { Não há necessidade de ajuste na formulação lingüistica. } \\
\text { •Perspectiva Motora } \\
\text { Näo há necessidade de ajuste temporal ao interlocutor. }\end{array}$ \\
\hline ABORDAGEM 3 & $\begin{array}{l}\text { - Desativaçăo do Paradoxo Básico pela ausência de receio de } \\
\text { julgamento, eliminando-se os truques. }\end{array}$ \\
\hline ABORDAGEM 4 & - Ausência de antecipaçăo da gagueira e de ansiedade. \\
\hline
\end{tabular}

Figura 9 - Justificativas para a ausência de disfluências gagas no monólogo com base nas abordagens estudadas 


\section{DISCUSSÃO}

As abordagens estudadas estão embasadas em diferentes correntes do pensamento científico, o que determina olhares diferenciados. As abordagens 1 e 2 adotam a perspectiva das Ciências Naturais, apresentando modelo metodológico ${ }^{5}$ que prioriza experimentação, relações causais e uso de métodos quantitativos e estatísticos. A gagueira assume a dimensão de objeto autônomo ${ }^{7}$, de fato ${ }^{43}$, que pode ser assimilado pela apreensão objetiva de seus elementos, leis e características. A abordagem 3 adota a corrente do Materialismo Dialético em Ciências Humanas, apresentando modelo que busca entender o fato dentro de uma perspectiva contextualizada, histórica e processual ${ }^{12}$; a construção da gagueira ocorre no contexto relacional (sujeito - meio) e em função dele, sendo impossível dissociá-los ${ }^{7}$. A abordagem 4 adota a corrente Fenomenológica em Ciências Humanas ${ }^{3,6,14,41-43}$, apresentando modelo que desconsidera o superficialmente observável, priorizando a busca da essência sem estabelecer relações causais ou considerar hipóteses prévias ${ }^{14}$. Adota a concepção de que o todo está em cada parte, assumindo a gagueira a dimensão de parte do sujeito, uma possibilidade de ser dentre tantas outras. É vista na relação subjetiva intra-sujeito.

A corrente de pensamento adotada direciona teoria e prática, determinando semelhanças e diferenças entre as abordagens. Assim, 1 e 2 adotam a concepção científica clássica, vendo a gagueira como objeto em si, em oposição às abordagens 3 e 4, que a analisam em sua subjetividade, intra-sujeito em 4 e contextual em $3^{45}$.

A definição da gagueira é uma questão controversa $^{1,3,4}$, refletindo a diversidade que o assunto permite. A abordagem 1 define a gagueira ${ }^{24}$ pela descrição dos comportamentos observáveis, privilegiando a caracterização das rupturas e dos movimentos associados; a abordagem 2 inclui a descrição em sua definição ${ }^{9,29,30}$, entretanto a associa com a implicação do efeito das experiências do falante com as reações negativas e as limitações que este sujeito passa a vivenciar; a abordagem 3 , adotando a perspectiva da auto-avaliação ${ }^{11}$, declina das descrições, retirando o foco sobre a manifestação e colocando-o na constituição da auto-imagem de falante; a abordagem 4, propõe que a Gagueira não seja definida ${ }^{3,41,42}$ por entender que a definição provoca uma redução do que se quer definir ${ }^{3}$.

A análise do aspecto etiologia mostra similaridade entre as abordagens $1^{16,24-28}$ e $2^{9,13,29,31-36}$ apoiadas na concepção organicista, apontando para a presença de falhas no processamento lingüístico e / ou motor da fala, responsável pelas rupturas, considerando o fator genético como predisponente básico para a gagueira. A abordagem 2 soma aos fatores genéticos os traços psicológicos e os fatores ambientais ${ }^{30}$, fazendo uma ponte com a proposta da abordagem $3^{7,11,12,15,39,40}$ que coloca, entretanto, a dialética interno $\mathrm{x}$ externo como fator principal na construção do que chamou de Gagueira Sofrimento. A abordagem $4^{6,14,41,42}$ aponta a hereditariedade como fator presente na construção da gagueira, porém, não se detém no fato, uma vez que entende ser herdada a possibilidade de gaguejar, e não a Gagueira Construída, resultante da não aceitação desta possibilidade. É importante considerar que, embora haja similaridade no apontamento de alguns aspectos relacionados à etiologia, devem-se guardar as devidas diferenças quanto à importância desse aspecto na instalação da gagueira para cada abordagem.

A forma de avaliar a gagueira ou o indivíduo que gagueja está diretamente relacionada à concepção teórica que se tem sobre a mesma. Uma questão conceitual aqui se impõe. A análise qualitativa na visão das abordagens 1 e 2 prevê descrição dos comportamentos manifestos, analisando-os a partir de parâmetros pré-estabelecidos ${ }^{24-27,30,37}$. Implica classificação da gagueira quanto ao tipo e severidade, sendo associada à avaliação quantitativa. Para a abordagem 4 avaliar qualitativamente significa perceber $e$ descrever a gagueira daquele sujeito específico, sem parâmetros prévios, entendendo como necessária a diferenciação entre a avaliação do gago, num processo subjetivo, e da gagueira, com a identificação do seu mapeamento muscular. Não há intenção de comparar ou classificar, não vendo sentido na avaliação quantitativa por acreditar que nada diz sobre a gagueira ${ }^{3}$. Na abordagem 3 , avaliar qualitativamente significa entender, pela análise do discurso, o que subjaz à gagueira e a constitui, o funcionamento da consciência do sujeito, não tendo relação com a descrição dos comportamentos; declina da avaliação quantitativa, entendendo que não é a quantidade de rupturas que determina o diagnóstico e a necessidade de intervenção ${ }^{11}$.

Avaliar a gagueira, nas abordagens 1 e 2 significa localizá-la dentro de uma escala estabelecida previamente, entretanto, a abordagem 2 avança da questão descritiva considerando a dimensão da auto-avaliação do sujeito; para a abordagem 4 significa entender sua construção naquele sujeito, e para abordagem 3 reconhecer o sofrimento do sujeito, identificado com a auto-imagem de mau falante.

Quanto ao aspecto modelo terapêutico, a abordagem 1 adota a perspectiva do Modelamento da Fluência ${ }^{4}$, uma vez que preconiza o trabalho com a respiração, fonação, articulação, prosódia e estimulação das habilidades auditivas; a autora da abordagem 2 se auto-classifica na perspectiva da Promoção da Fluência ${ }^{4,32}$, adotando estratégi- 
as como a suavização do início da emissão e a resistência à pressão do tempo, além de estratégias como a disfluência voluntária e a flexibilização dos parâmetros de fala, propiciando a redução da ansiedade e medo para falar. A abordagem 3, na medida em que promove a eliminação dos truques para evitar a gagueira pela ressignificação da imagem de falante, aproxima-se da perspectiva de Modificação da gagueira ${ }^{4}$, guardada a devida especificidade de referencial teórico, uma vez que a eliminação dos truques / evitação aparece como conseqüência e não como estratégia de modificação na subjetividade do sujeito. A abordagem 4 adota processo terapêutico que implica o conhecimento sobre o funcionamento da gagueira e da fluência, a conscientização do corpo e da fala, e a percepção dos sentimentos do sujeito frente a sua produção verbal, assumindo tanto a perspectiva da Promoção da Fluência quanto da Modificação da Gagueira ${ }^{4}$.

É interessante notar que algumas estratégias usadas pelas autoras são semelhantes, assumindo conotação e importância diferentes conforme o referencial teórico. A técnica gagueira voluntária, para a abordagem $3{ }^{11}$, propicia a supressão das emoções negativas e favorece a modificação do padrão de tentar falar bem, permitindo uma sensação de domínio sobre a gagueira; para a abordagem $2^{4,32}$ visa possibilitar a percepção de que as disfluências comuns fazem parte da fala de todos, reduzindo a ansiedade e o medo de gaguejar. Para a abordagem 3 permite a eliminação do paradoxo básico, elemento fundamental na instalação da gagueira; para a abordagem 2, atua numa das dimensões que a constituem, o psicológico.

Outro exemplo interessante é a técnica Abordagem Corporal, fundamental para a abordagem $4{ }^{41-44}$, na medida em que considera a construção da gagueira no corpo. Entende como indispensável a conscientização da relação tensão muscular e emoção, e o trabalho com o reequilíbrio muscular para a dissolução dos invólucros. Para abordagem $3{ }^{11}$, significa a percepção do estado de tensão e esforço ao falar, resultante da tentativa de evitar / fugir da gagueira. Sugere o trabalho de relaxamento, objetivando a vivência da fluência e o aumento da confiança na capacidade de falar, modificando o estado de consciência frente à fala. Para abordagem $2{ }^{4}$ implica em perceber a tensão muscular, objetivando a mudança voluntária para a harmonia da musculatura, auxiliando na promoção da fluência. Assim, é possível perceber que mesmo adotando técnica semelhante, a função que esta ocupa no processo terapêutico está vinculada à perspectiva teórica da autora.

Finalizada a análise comparativa, resta cumprir o segundo objetivo: justificar a ausência de disfluências gagas no monólogo com base nas teorias apresentadas.
Na Abordagem 1 deve-se considerar a perspectiva do conceito pressão do tempo ${ }^{24,25}$. Durante o diálogo, o indivíduo gago, por ser portador de um déficit de sincronia entre os sistemas neurais que processam os componentes lingüísticos e paralinguísticos gerando lentificação da produção, tenta se ajustar ao tempo do interlocutor, o que implica o uso de velocidade acima da ideal para sua habilidade, promovendo incremento na gagueira. Em situação de monólogo, a ausência de interlocutor permite o uso de velocidade confortável e livre de pressões, eliminando as disfluências gagas. Outra perspectiva de entendimento é a questão pragmática, da intenção do discurso, comandada pela etapa do conceitualizador ${ }^{24,25}$. As palavras de grande significado para o falante tendem a apresentar maior probabilidade de gagueira, porém, como no monólogo não há intenção comunicativa ${ }^{10}$, a perspectiva do conteúdo "perde importância", reduzindo-se as disfluências.

A abordagem 2, em uma perspectiva de multicausalidade ${ }^{9,13,29,31-36}$, pontua a relação entre demanda social e capacidade do indivíduo. Referindo-se à capacidade lingüística, esclarece que dificuldades em evocar palavras, gerar combinações fonologicamente corretas e formular sentenças, associadas à exigência social quanto à formulação e complexidade das estruturas lingüísticas definem a cronificação da gagueira. Destaca também, quanto à capacidade motora de execução, que quando há déficit de movimentação rápida e suave das estruturas, associada à exigência do meio quanto à velocidade de fala, ou auto-exigência em adequar-se ao tempo do interlocutor, haverá possibilidade de cronificação do quadro. Nesta perspectiva, no monólogo não há necessidade de ajustes na velocidade ou na formulação lingüística, usufruindo de liberdade para a formulação e execução da fala, eliminando as disfluências gagas.

A abordagem 3 identifica a ausência de gagueira no monólogo ${ }^{7,11,15,40}$ pontuando a estreita relação entre fala com gagueira e o contexto de comunicação ${ }^{7}$. Nesta proposta, a presença do outro, para um indivíduo identificado com a imagem estigmatizada de falante, provoca a ativação emocional, deflagrando o uso dos truques, o aumento de tensão muscular para falar e conseqüente intensificação da manifestação ${ }^{11}$. No monólogo desativa-se o paradoxo básico, não havendo planejamento prévio por receio de julgamento ${ }^{12}$, sendo eliminados os truques e, conseqüentemente, o incremento de tensão muscular e a gagueira.

A abordagem 4 pontua que não saber com-viverno-mundo-com-os-outros ${ }^{6}$, pode gerar emoções que levam ao desequilíbrio fisiopsíquico e conseqüente desequilíbrio muscular, comprometendo a fala. No monólogo, mediante a ausência do Outro, não há antecipação da gagueira e nem ansiedade ${ }^{44}$, não ocorrendo o desequilíbrio muscular, que leva ao padrão errático e incoordenado, deixando de produzir a 
gagueira. Comenta, ao descrever sua proposta terapêutica ${ }^{41}$, que ao modificar o sentimento de medo frente à reação do outro, modifica-se a relação com a gagueira e o indivíduo torna-se livre para monitorar as mudanças musculares necessárias para a fluência. Dessa forma, pode-se considerar que a condição de medo também desaparece no monólogo, eliminando as disfluências gagas.

Com base no exposto acima, é possível considerar que a gagueira tem implicações de natureza interpessoal, pois, seja justificada pela necessidade de ajustes lingüísticos, pela pressão do tempo, pela antecipação, ou pelo incremento dos truques para evitar a gagueira, a presença do Outro (interlocutor) provoca modificações no falante e conseqüentemente em sua fala, promovendo / intensificando a gagueira. A partir desta observação, fica evidente a necessidade de se considerar a dimensão das relações interpessoais no processo terapêutico.

\section{CONCLUSÃO}

A análise comparativa permitiu identificar semelhanças entre as Abordagens 1 e 2 nas propostas de Avaliação e Terapia, e semelhança parcial em Definição e
Etiologia; entre as Abordagens 2 e 3, semelhança parcial em Definição, Etiologia e Avaliação; entre as Abordagens 2 e 4, semelhança parcial em Etiologia, Avaliação e Terapia; entre as Abordagens 1 e 3, semelhança parcial na proposta de Avaliação; entre as Abordagens 1 e 4, semelhança parcial em Etiologia, Avaliação e Terapia e entre as Abordagens 3 e 4, semelhança quanto a avaliação, e semelhança parcial quanto Etiologia e Terapia. A comparação entre as Abordagens mostrou que, embora existam semelhanças entre elas, a especificidade dada pelo referencial teórico implica em diferenças conceituais e práticas, determinando a parcialidade das semelhanças.

Foi possível formular justificativas teoricamente embasadas para a ausência de disfluências gagas no monólogo, tomando por base as quatro abordagens, considerando a perspectiva da pressão do tempo e da pragmática na abordagem 1 , a perspectiva da habilidade do indivíduo em relação à demanda social na abordagem 2 , a perspectiva da ausência de receio de julgamento na abordagem 3 e a perspectiva da ausência de antecipação da gagueira, de ansiedade e de medo na abordagem 4. Estes achados apontam para a importância de considerar a dimensão das relações interpessoais na terapia.

\begin{abstract}
Purpose: this research is a comparative analysis between four different approaches on stuttering, by investigating the line of scientific thought of each author, definition, etiology, evaluation, therapy and raises some hypothesis to justify the absence of dysfluency in a monologue. Methods: a systematic bibliographic revision of the authors' publications: Ana Maria Schiefer, Claudia Regina Furquim de Andrade, Silvia Friedman and Isis Meira, so designed as approaches 1, 2, 3 and 4. Results: the comparative analysis identified similarities: Definition - between 1 and 2 about descriptive character, between 2 and 3 about self-evaluation; Etiology: between 1, 2 and 4 about the organic factor, between 2, 3 and 4 about psychological implications and between 2 and 3 about environmental; Evaluation - between 1 and 2 about quantitative criteria, between 1, 2, 3 and 4 about qualitative; Therapy - between 1 and 2 . The absence of dysfluency was justified by the perspectives: in 1, the time pressure and the pragmatic; in 2 , of the Neurolinguistics and Motor adjusts; in 3, about the basic paradox and in 4, of the anticipation, anxiety and fear. Conclusion: similarities were found between 1 and 2 on the definition, etiology, evaluation, and therapy; between 1 and 3 about evaluation; between 2 and 3 about definition, etiology and evaluation; between 1 and 4, 2 and 4, 3 and 4, about etiology, evaluation and therapy. The similarities have been partial due to the specificity of theoretical referential of each approach. The absence of speech dysfluency was justified by the inexistence of adjustment to the interlocutor, and the communicative intention in 1 , of adjust in the linguistic formulation and temporal in 2, due to the absence of fear of judgment in 3 and the anticipation of anxiety and fear in 4.
\end{abstract}

KEYWORDS: Stuttering; Communication; Interpersonal Relations

\section{AGRADECIMENTOS}

À Prefeitura Municipal de São Caetano do Sul, gestão do Sr. Prefeito Dr. José Auricchio Junior, e ao Sr. Leopoldo Koerner, pelo apoio ao Curso de Especialização e a este estudo.

\section{REFERÊNCIAS}

1.Spinelli M. Gagueira: análise de pesquisas e casos clínicos. In: Friedman S, Cunha MC, organizadoras. Gagueira e subjetividade: possibilidades de tratamento. São Paulo: Artmed; 2001. p. 15-32. 
2.Meira I. Apresentação. In: Meira I, organizadora. Tratando gagueira: diferentes abordagens. São Paulo: Cortez; 2002. p. 7-12.

3.Meira I. Gagueira. In: Goldfeld M. Fundamentos em fonoaudiologia: linguagem. Rio de Janeiro: Guanabara Koogan; 1998. p. 53-68.

4.Andrade CRF. Programa fonoaudiológico de promoção da fluência em adultos gagos: tratamento e manutenção. In: Limongi SCO. Fonoaudiologia: informação para a formação. Rio de Janeiro: Guanabara Koogan; 2003. p. 27-53.

5.Leopardi MT. Correntes de pensamento na ciência e na pesquisa. In: Leopardi MT. Metodologia da pesquisa em saúde. Florianópolis: UFSC; Pós-graduação em Enfermagem; 2002. p. 63-92.

6.Meira I. Gagueira: uma análise qualitativa. Distúrb Comun. 1990; 3(2):205-18.

7.Friedman S. Gagueira: origem e tratamento. São Paulo: Summus; 1986. 143 p.

8. leto V, Kelly REOG. "Olha para mim...": a gagueira como demanda de reconhecimento no espaço familiar. Distúrb Comun. 2003; 14(2):361-77.

9.Andrade CRF. Abordagem neurolinguística e motora da gagueira. In: Ferreira LP, Befi-Lopes D, Limongi SCO, organizadoras. Tratado de fonoaudiologia. São Paulo: Roca; 2004. p. 1001-16.

10. Leir - De Vitto M F. Os monólogos da criança: delírios da língua. São Paulo: Educ; 1998. 181 p.

11. Friedman S. Reflexões sobre a natureza e o tratamento da gagueira. In: Passos MC, organizadora. Fonoaudiologia: recriando seus sentidos. Série Interfaces. São Paulo: Plexus; 1996. p. 81-117.

12. Friedman S. Fluência: um acontecimento complexo. In: Ferreira LP, Befi-Lopes D, Limongi SCO, organizadoras. Tratado de fonoaudiologia. São Paulo: Roca; 2004. p. 1027-34.

13. Andrade CRF. A história natural da gagueira: estudo dos 0 aos 24 meses de vida. Pró-fono. 2000; 12(1):60-8. 14. Meira I. Abordagem fenomenológica da fluência. In: Ferreira LP, Befi-Lopes D, Limongi SCO, organizadoras. Tratado de fonoaudiologia. São Paulo: Roca; 2004. p. 1017-26.

15. Friedman S. A construção do personagem bom falante. São Paulo: Summus; 1994. 185 p.

16. Schiefer AM. Considerações preliminares entre uma possível correlação entre gagueira e os aspectos lingüísticos e auditivos. Pró-fono. 1999; 11(1):27-31.

17. Cunha MC. Fonoaudiologia e psicanálise: uma reflexão sobre a gagueira e o inconsciente. In: Passos MC, organizadora. Fonoaudiologia: recriando seus sentidos. Série Interfaces. São Paulo: Plexus; 1996. p. 69-79.

18. Ferriolli BHVM. Contribuições da análise de discurso na clínica da gagueira. Disponível em: URL: http://www.abragagueira.org.br/ferriolli.html 19. Messenger M, Onslow M, Packman A, Menzies R. Social anxiety in stuttering: measuring negative social expectancies. J Fluency Disord. 2004; 29(3):201-12. 20. Ezrati-Vinacour R, Levin I. The relationship between anxiety and stuttering: a multidimensional approach. J Fluency Disord. 2004; 29(2):135-48.

21. Alm PA. Stuttering, emotions, and heart rate during anticipatory anxiety: a critical review. J Fluency Disord. 2004; 29(2):123-33.

22. Weiss AL. We should consider pragmatics when planning treatment for children who stutter. Lang Speech Hear Serv Sch. 2004; 35(1):34-45.

23. Venkatagiri HS. Bridging the divide between laboratory and "real world" in stuttering. Percept Mot Skills. 2004; 99(1):95-104.

24. Schiefer AM. Abordagem psicolingüística da fluência. In: Ferreira LP, Befi-Lopes D, Limongi SCO, organizadoras. Tratado de fonoaudiologia. São Paulo: Roca; 2004. p. 1035-9.

25. Schiefer AM. Gagueira: caracterização das disfluências e possíveis correlações com a audição e outros aspectos da fala [doutorado]. São Paulo (SP): Universidade Federal de São Paulo; 1999.

26. Arcuri CF, Ishii C, Schiefer AM, Pereira LD. Fatores de risco auditivo em indivíduos gagos. Fono Atual. 2004; 28:4-10.

27. Degiovani VM, Chiari BM, Schifer AM. Disfluência: caracterização dos tipos e freqüência de ocorrência em um grupo de escolares. Pró-fono. 1999; 11:32-7. 28. Schiefer AM. Aspectos auditivos da gagueira: avaliação e tratamento. Disponível em: URL: http:// www.abragagueira.org.br/schiefer.html

29. Andrade CRF. História natural da gagueira - estudo I: perfil da fluência. Pró-fono. 2002; 14(3):351-60.

30. Andrade CRF. A gagueira e o processo da comunicação humana. In: Limongi SCO. Fonoaudiologia: informação para a formação: linguagem: desenvolvimento normal, alterações e distúrbios. Rio de Janeiro: Guanabara Koogan; 2003. p. 49-64.

31. Andrade CRF. Comparação entre os achados neurolinguísticos e neuroaudiológicos nas gagueiras. Pró-fono. 1999; 11(2):27-30.

32. Andrade CRF. Diagnóstico e intervenção precoce no tratamento das gagueiras infantis. Barueri: Prófono; 2004. 112 p.

33. Andrade CRF. História natural da gagueira - estudo II: sistema miofuncional oral e funções. Pró-fono. 2002; 14:361-70.

34. Andrade CRF, Meneghetti C, Sassi FC, Bertini F. Estudo diagnóstico de um caso de gagueira desenvolvimental com uso de Pet (Positron Emission Tomography). Pró-fono. 2001; 13:152-6.

35. Andrade CRF. História natural da gagueira - estudo III: vocabulário, fonologia e pragmática. Pró-fono. 2002; 14(3):371-82.

36. Andrade CRF. Processamento da fala: aspectos da fluência. Pró-fono. 2000; 12:69-71.

37. Andrade CRF. Protocolo para avaliação da fluên- 
cia da fala. Pró-fono. 2000; 12:131-4.

38. Andrade CRF, Befi-Lopes DM, Fernandes FDM, Wertzner HF. ABFW: teste da linguagem infantil nas áreas de fonologia, vocabulário, fluência e pragmática. Barueri: Pró-fono; 2004. 98 p.

39. Friedman S. Fluência: normalidade e patologia. Distúrb Comun. 1999; 11:131-6.

40. Friedman S. O caso de Amadeu. In: Friedman S, Cunha MC, organizadoras. Gagueira e subjetividade: possibilidades de tratamento. Porto Alegre: Artmed; 2001. p. 133-43.
41. Meira I. Método integrativo existencial: o caso de G. A. In: Meira I, organizadora. Tratando gagueira: diferentes abordagens. São Paulo: Cortez; 2002. p. 151-80. 42. Meira I. Enfoque corporal na terapia da gagueira. Disponívelem:URL: http://www.abragagueira.org.br/meira.html 43. Meira I. Gagueira: do fato para o fenômeno. São Paulo: Cortez; 1986. 144 p.

44. Meira I. Gagueira: um caso clínico. Fono Atual. 2000; 11:8-14.

Oliveira OS. Gagueira: a teoria na prática. Rev CEFAC. 1999; 1:56-64.

RECEBIDO EM: 4/12/2006

ACEITO EM: 02/03/2007

Endereço para correspondência:

Rua Tomaso Tomé, 160

São Caetano do Sul - SP

CEP: 09571-340

Tel.: (11) 42383840

E-mail: rosivânia10@terra.com.br 